\title{
Did Municipal Water Distribution System Deficiencies Contribute to a Legionnaires' Disease Outbreak in Quincy, IL?
}

\author{
William J. Rhoads, * Tim Keane, M. Storme Spencer, Amy Pruden, and Marc A. Edwards \\ Cite This: Environ. Sci. Technol. Lett. 2020, 7, 896-902 \\ Read Online
}

ABSTRACT: Fifty-eight people were sickened and 12 died from a Legionnaires' disease (LD) outbreak in Quincy, IL, in 2015. The initial outbreak investigation identified deficiencies at the Illinois Veteran's Home (IVHQ), but these did not account for four community-acquired cases that occurred concurrently with no IVHQ exposure. We broaden the investigation to evaluate seven lines of evidence and assess whether municipal drinking water supply deficiencies potentially contributed to a community-wide outbreak. Notably, 3-6 months prior to the outbreak, the primary disinfectant was changed and corrosion control was interrupted, causing a sustained decrease in disinfectant residuals throughout

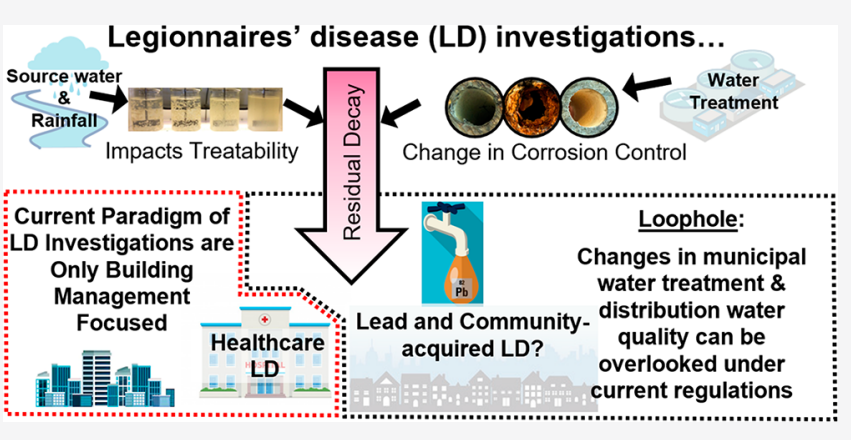
Quincy's distribution system. We hypothesize this created more favorable conditions for Legionella growth throughout the system and an increase in water lead levels. These municipal system deficiencies were not identified in prior investigations of the outbreak, but their impacts on public health outcomes are consistent with those of the 2014-2016 Flint Water Crisis. However, they occurred in Quincy without any legal violations in the municipal water system or public acknowledgment of community-wide health risks. This study supports the critical need for improved data collection during changes in municipal water treatment. Additional regulatory and communication requirements can better protect public health from both LD and lead.

\section{INTRODUCTION}

Legionnaires' disease (LD) outbreak investigations typically focus on building water system deficiencies known to enable proliferation of Legionella, including water temperature within Legionella's growth range $\left(25-49^{\circ} \mathrm{C}\right)$, stagnation, and lack of disinfectant residual. ${ }^{1-4}$ While investigations rarely examine and report factors associated with municipal water treatment and distribution, such external factors have been recognized as contributors to LD incidence and/or outbreaks, including major rainfall events, ${ }^{5,6}$ pressure fluctuations, excavation associated with construction activities, ${ }^{7}$ water main breaks, and changes in disinfectant residuals. ${ }^{7-11}$ Given that LD is widely underreported, with $1.9-5.5 \%$ of all pneumonia-related hospitalizations in the United States estimated to be due to LD under non-outbreak conditions, ${ }^{5,11,12}$ community-acquired pneumonia cases are expected to increase during a community-wide LD outbreak. ${ }^{11,13}$

A LD outbreak that occurred in Flint, MI, in 2015-2016, resulting in $>90$ cases and 13 deaths, recently brought to light the importance of considering municipal water system-level challenges and/or deficiencies in outbreak investigations. ${ }^{14-16}$ Specifically, after the City of Flint switched from Lake Huronsourced water dosed with orthophosphate corrosion control to Flint River-sourced water with no corrosion control, the water corroded iron mains and lead service lines and caused elevated water and blood lead levels (WLLs and BLLs, respec- tively). ${ }^{17,18}$ The widespread iron corrosion rapidly consumed free chlorine disinfectant residual, likely contributing to LD in Flint. ${ }^{14,15,19}$ Consistent with the idea that LD often goes undetected, there were 90 excess pneumonia deaths estimated in Flint during the 18-month Flint Water Crisis (FWC) that may have been undetected LD. ${ }^{13}$

Here we broaden the investigation of a severe 2015 LD outbreak in Quincy, IL, to include problems with the municipal water system that could have contributed to the outbreak. The majority of cases and/or deaths occurred at the Illinois Veteran's Home (IVHQ), with negligence lawsuits related to the LD deaths that occurred at the IVHQ recently settled without fault for approximately $\$ 6.4$ million. $^{20}$ However, the timeline of the primary IVHQ deficiencies identified was not consistent with the exposure/incubation period of the first case associated with IVHQ and does not explain a cluster of five community-acquired LD cases in the City of Quincy with no known exposure to IVHQ (8.7\% of the

Received: August 12, 2020

Revised: September 21, 2020

Accepted: September 21, 2020

Published: September 21, 2020 
total cases). ${ }^{20}$ Specifically, we examine the impacts of a 100 year storm that occurred a few weeks prior to the first cases, ${ }^{21}$ a period of interrupted phosphate corrosion control, and a change in primary disinfectant at the water treatment plant on municipal water distribution system disinfectant residuals. Seven lines of evidence are examined to assess the hypothesis that these events created favorable Legionella growth conditions that were amplified in locations where there were already preexisting water quality or water management issues. There are striking similarities between Flint and Quincy, wherein a chain of events precipitated by changes in drinking water treatment negatively impacted public health. However, the water quality issues encountered in Quincy occurred in the absence of the violation of any state or federal drinking water laws, evidence of wrongdoing on the part of public servants, or public outcry over water safety as was the case in Flint. The findings herein bring to light the urgent need to consider municipal water system problems as a contributing factor in LD outbreak investigations and for improved regulation and policies to better protect public health from both lead and Legionella.

\section{MATERIALS AND METHODS}

Water Quality and Blood Lead Data. Water quality data routinely collected at the treatment plant and distribution system monitoring stations were obtained through Quincy Public Records Requests (https://www.quincyil.gov/engage/ open-gov-t/public-info/public-records-request) for Monthly Operations Reports (MORs). Lead and Copper Rule (LCR) compliance sampling data were obtained from the EPA Drinking Water Watch Webpage (http://water.epa.state.il.us/ $\mathrm{dww} /$ index.jsp; Quincy water system ID IL0010650) and Quincy Public Records Requests. BLL data were collected from the Illinois Department of Public Health (IDPH) public records request (http://www.dph.illinois.gov/foia).

Reported Pneumonia Deaths. Nonviral pneumonia (ICD-10 Codes J15, 16, and 18) and Legionella-related (ICD-10 codes A48.2 and 48.2) death numbers were extracted from the CDC WONDER Multiple Cause of Death database by year from 1999 to 2018. Adams County is classified as "micropolitan" using the National Center for Health Statistics 2013 Urbanization Classifications based on county population; therefore, we selected all micropolitan counties in Illinois and bordering states (Iowa, Missouri, Wisconsin, Kentucky, and Indiana) as controls $(n=100)$.

Data Analysis and Statistics. Data analysis was performed in RStudio using $\mathrm{R}$ version 3.5.1. Statistical analyses are described in the text or in the Supporting Information, where the R-code used can also be found.

\section{RESULTS AND DISCUSSION}

After re-evaluating the timeline and previously identified water system deficiencies that contributed to the LD outbreak at the IVHQ we factor in publicly available data demonstrating that the municipal water supply was experiencing problems we hypothesize contributed to LD incidence in Quincy and the release of lead to the water.

Evidence Supports That There Was a Communitywide LD Outbreak in Quincy. The initial investigation of the Quincy LD outbreak cited numerous deficiencies specific to the potable water systems serving the IVHQ campus, including the age of the campus plumbing system, poor maintenance practices, malfunctioning equipment, inadequate hot water temperatures $\left(<120{ }^{\circ} \mathrm{F} ;<49{ }^{\circ} \mathrm{C}\right)$, design and recirculation issues, lack of backflow prevention devices, and an overall lack of a water management plan. ${ }^{20}$ In particular, IDPH and IVHQ staff identified a central water heater storage tank that had been offline for maintenance and stored stagnant at ambient temperature from July to August 6, 2015. When the water heater tank was repaired, it was reheated to $49{ }^{\circ} \mathrm{C}(120$ ${ }^{\circ} \mathrm{F}$ ) and placed back into service, which, in combination with all of the other issues identified, has been hypothesized to have been a key trigger for the LD outbreak. However, the timeline is not consistent with the occurrence of the first confirmed healthcare-acquired IVHQ LD case (July 24, more than 2 weeks before the tank was placed back into service) and does not explain the incidence of five community-acquired LD cases with no known exposure to the IVHQ (Figure 1).

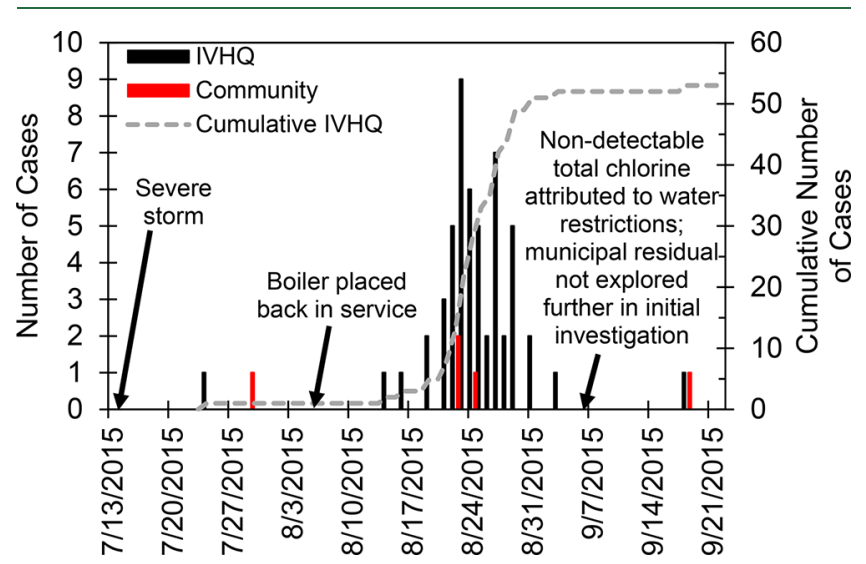

Figure 1. Confirmed legionellosis cases in Adams County by date of symptom onset with several potential contributing events highlighted. IVHQ denotes cases with known exposure to IVHQ facility; Community denotes cases in Adams County with no known exposure to the IVHQ. Nondetectable levels of total chlorine residual on IVHQ's campus were reported in the CDC site investigation but were assumed to be low because water restrictions had been in place for 6 days at IVHQ following the identification of the outbreak and thus potentially not representative of disinfectant residual levels during the onset of the outbreak. Distribution system total chlorine residuals at the the municipal level, which are presented in Figure 2, were not previously reported or analyzed in detail. ${ }^{20}$

The five community cases of LD, which occurred within 40 days of one another and concurrently with the larger IVHQ outbreak, were attributed to sporadic community-acquired cases by investigators. ${ }^{20}$ However, we note that four of the five LD case investigations pertained to individuals living in Quincy and with no identified common exposures (SI-Section 1). The fifth community case, which occurred in September, did have potential exposure to a known hotel outbreak in another community, and a different sequence type of Legionella pneumophila was isolated from the patient's sputum than what was found at the IVHQ. However, it is not uncommon in community outbreak investigations to detect multiple strains of Legionella in environmental and clinical samples, ${ }^{22-25}$ and this fifth case resided within 1 mile of the IVHQ. Although historical LD occurrence data in Adams County were not available, it is reasonable to consider a cluster of four community-acquired LD cases in a small city ( $\sim 40000$ people; $\sim 75000$ people in the metro area) in less than a 40 day window as an unusually high LD incidence (i.e., 5-10 times 
higher than the 2015 national incidence of LD). It should also be noted that there were no on-site LD testing capabilities at Quincy community healthcare facilities at the time, and testing for suspect cases was focused on having IVHQ expsoure. ${ }^{26}$ Thus, it is likely that other LD cases could have gone undetected $^{26}$ that would have benefitted from a broader outbreak investigation in the community.

A severe storm and nondetectable disinfectant residual on the IVHQ campus were mentioned in the initial CDC outbreak report. However, the nondetectable residual measured during the CDC outbreak investigation was attributed to water use restrictions that had been in place for 6 days, ${ }^{20}$ and additional analysis of the storm or municipal distribution disinfectant residuals was not included in any report we examined. $^{20}$ The storm and low disinfectant residuals are consistent with additional potential root causes of the July 24 IVHQ LD case and community-acquired LD cases not associated with IVHQ (Figure 1).

A Record Storm Caused Treatment Disturbances. On July 13,2015 , approximately 1 week before the first LD case at IVHQ and 2 weeks before the first community-acquired LD case in Quincy, there was a 100-year storm event with heavy rainfall and severe wind damage across Adams County (Figure 1). Raw water turbidity spikes during periods of increased rainfall correlated with flow rate (i.e., "river stage”) of Quincy's Mississippi River source water [Spearman Rank; $\rho=0.54 ; p$ value $<2.2 \times 10^{-6}$ (SI-Section 2)]. Spikes in raw water turbidity above $60 \mathrm{NTU}$ (the 85th percentile turbidity from 2015-2019; median $=31.5$ NTU) were associated with lower total chlorine residuals entering the municipal distribution system ( $t$ test $p$ value $<0.05$ ), with the maximum recorded turbidity associated with the July 2015 storm (247 NTU, >99.9 percentile turbidity 2015-2019) corresponding to a predicted decrease of $>0.35 \mathrm{mg} / \mathrm{L}$ total chlorine entering the distribution system. Disinfectant residuals in the distribution system can decrease due to reactions with organic matter associated with raw water turbidity spikes during rainfall events. This is consistent with prior reports that $\mathrm{LD}$ cases can spike up to 2 weeks after severe rainfall events. ${ }^{5,6}$ These prior reports hypothesized that the source of increased LD after rainfall was due to an increase in the number of environmental sources of Legionella, but such sources have not been definitively linked to LD incidence. ${ }^{5,6}$ Data presented here support the prior hypothesis that storms may impact drinking water treatability ${ }^{5}$ and alter distribution system residuals. This hypothesis is deserving of increased future scrutiny.

Alterations in Water Treatment Contributed to Lower Disinfectant Residuals in the Distribution System. Two to seven months prior to the 2015 LD outbreak, the Quincy municipal water treatment plant made major changes that contributed to lower disinfectant residuals in the distribution system. One change included altering the primary disinfectant used from free chlorine to chloramine (from December 2014 to May 2015). Within 1 month, total chlorine in the distribution system was $50 \%$ of that of the same time period when free chlorine was used the previous year (i.e., median total chlorine of $3.5 \mathrm{mg} / \mathrm{L}$ in January-May 2014 decreased to $1.75 \mathrm{mg} / \mathrm{L}$ in 2015). While there appears to be a seasonal decrease in distribution system residuals from September to August, the levels in 2015 were chronically lower for nearly an entire year. We further discovered that phosphate corrosion control was discontinued for seven months (from May 2015 to February 2016) during upgrades to the water treatment plant, without any other corrosion control plan to the best of our knowledge. During this period, total chlorine levels in the distribution system were $50 \%$ lower than the same time period in the previous year (i.e., median total chlorine from May 2014 to Februrary 2015 of $2.65 \mathrm{mg} / \mathrm{L}$ decreased to $1.32 \mathrm{mg} / \mathrm{L}$ from May 2015 to February 2016).

After the LD outbreak was recognized, the Quincy water treatment plant markedly increased the dose of disinfectant residual entering the municipal distribution system (often $>4$ $\mathrm{mg} / \mathrm{L}$ ), yet $17 \%$ of distribution system samples were still $<1$ $\mathrm{mg} / \mathrm{L}$ total chlorine (Figure 2), consistent with a high chlorine

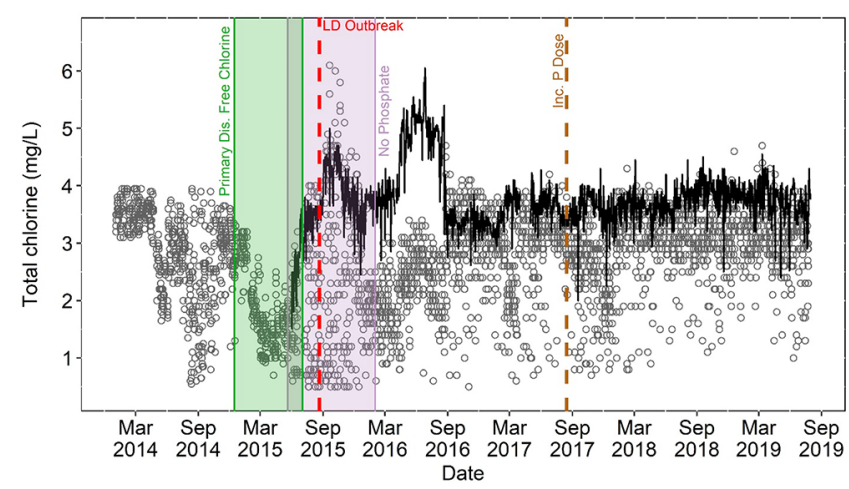

Figure 2. Total chlorine levels in treated water entering the municipal distribution system (black line) and at distribution system monitoring points (gray circles) in Quincy, IL. Chloramine was temporarily used as the primary disinfectant (green shading), and phosphate corrosion inhibitor addition was disrupted (purple shading). The recognition of LD outbreak (red dashed line) and increased phosphate dose (gold dashed line) are annotated.

demand due to an elevated level of iron corrosion without phosphate corrosion control, as observed during the FWC. ${ }^{14}$ After the water treatment plant upgrades were completed, free chlorine was again used to achieve primary disinfection (starting November 2015) and phosphate was reintroduced (February 2016). By September 2016, distribution system total chlorine levels had approximately doubled to a median of 3.0 $\mathrm{mg} / \mathrm{L}$ relative to $1.32-1.75 \mathrm{mg} / \mathrm{L}$ observed when using chloramine as a primary disinfectant and/or during the lapse in phosphate dosing. Notably, only one sample during the phosphate lapse violated the Illinois distribution system requirement at that time to maintain $0.5 \mathrm{mg} / \mathrm{L}$ at all times. ${ }^{27}$ While we recognize that Quincy was achieving state-required minimum disinfectant residuals, we hypothesize that the decrease in disinfectant residuals in the distribution system [i.e., distribution system monitoring indicating lower residuals compared to historical norms, despite the increased dosing at the water treatment plant (Figure 2)] contributed to conditions that support Legionella growth in buildings, especially in locations where there were other significant water system deficiencies, such as at IVHQ.

Underreporting of Community-Acquired LD. Considering that only an estimated $10.6 \%$ of LD cases are diagnosed, ${ }^{12}$ we investigated nonviral pneumonia deaths that potentially reflect undetected LD. Adams County has consistently had high incidence of pneumonia deaths relative to similar micropolitan counties in the region, but it exhibited a sharp increase in 2015 (i.e., the 99th percentile of 100 control counties) relative to the generally decreasing trend (Figure $3 \mathrm{~A})$. The crude pneumonia death rates were predicted for all 

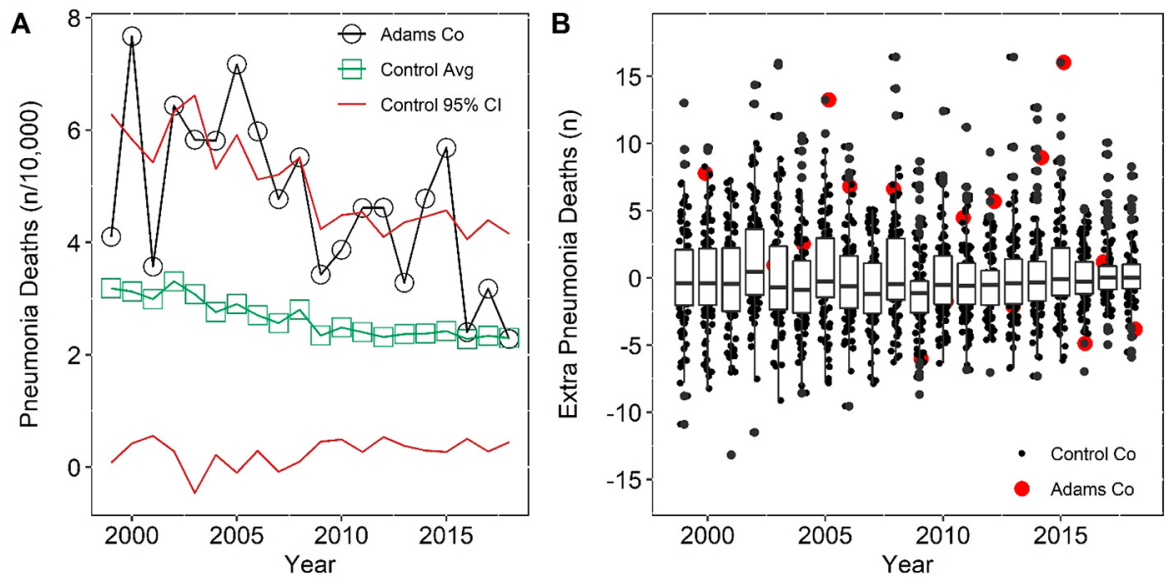

Figure 3. (A) Crude pneumonia death rate (per 10000 people) by year. Ctrl denotes control counties (micropolitan counties in Iowa, Illinois, Indiana, Kentucky, Missouri, and Wisconsin). The average (green squares) and Poisson 95\% confidence interval (red lines) are reported for the control counties. (B) Box plot of residuals from generalized linear regression models of crude pneumonia death rate for each county by year, representing extra pneumonia-related deaths by year (see SI-Section 3). Box plots represent 25th, 50th, and 75th percentiles, and whiskers represent 1.5 times the interquartile range.

\begin{tabular}{|c|c|c|c|c|c|}
\hline Statistic & 2012-2014 & 2015-2017 & 2018-2020 & p-value & $\mathrm{N}$ \\
\hline $90^{\text {th }}$ Percentile & 1.3 & 9.2 & $<1$ & & 30 \\
\hline \multirow{3}{*}{$\begin{array}{l}\text { Mean of All } \\
\text { Paired Data }\end{array}$} & 1.31 & 3.60 & - & 0.036 & 21 \\
\hline & - & 3.61 & 0.47 & 0.00027 & 21 \\
\hline & 1.28 & - & 0.47 & $<0.0001$ & 25 \\
\hline \multirow{3}{*}{$\begin{array}{c}\text { Mean of Paired } \\
\text { Data with at } \\
\text { Least } 1 \text { Data } \\
\text { Point }>Q \text { L }\end{array}$} & 1.93 & 8.81 & - & 0.036 & 7 \\
\hline & - & 4.23 & 0.51 & 0.0010 & 17 \\
\hline & 1.53 & - & 0.72 & 0.017 & 13 \\
\hline \multirow{3}{*}{$\begin{array}{c}\text { Mean of All } \\
\text { Data (not } \\
\text { paired) }\end{array}$} & 1.2 & 4.33 & - & 0.082 & 30 \\
\hline & - & 4.33 & 0.43 & 0.0027 & 30 \\
\hline & 1.23 & - & 0.43 & $<0.0001$ & 30 \\
\hline
\end{tabular}

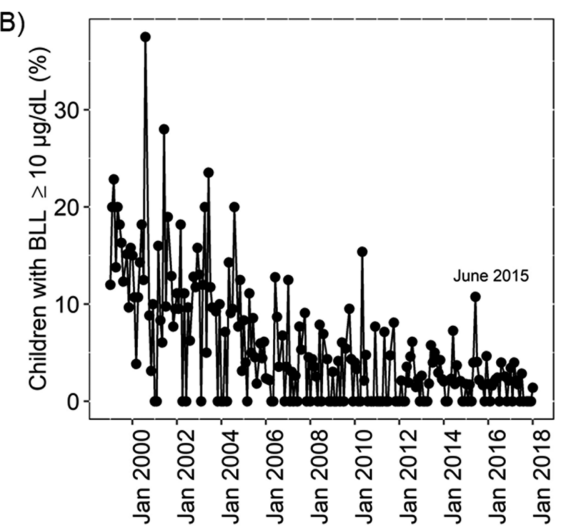

Figure 4. (A) Ninetieth percentile water lead levels (WLL) and Wilcox tests (unpaired and paired by sampling location) for samples reported by the City of Quincy for Lead and Copper Rule (LCR) compliance. (B) Percent of $<6$-year-old children with blood lead levels (BLLs) of $\geq 10 \mu \mathrm{g} / \mathrm{dL}$ in Adams County. The monitoring results from the month after the lapse in phosphate dose (June 2015; $n=65$ ) are indicated.

counties in Illinois and bordering states similar to Adams County $(n=100)$ using Poisson-distributed generalized linear models, excluding 2015, and deviations of observed versus predicted deaths were calculated to estimate "extra" pneumonia deaths occurring in 2015 (Figure 3B). In 2015, Adams County reported 16 extra pneumonia deaths relative to the predicted number (SI-Section 3). This relatively small increase (i.e., 5 more deaths than the $11 \mathrm{LD}$ deaths associated with the IVHQ in 2015) may reflect a lower mortality of communityacquired relative to healthcare-associated pneumonia. This effect is clearly reflected in the IVHQ outbreak data, wherein the mortality rate at the IVHQ was $32 \%$ for residents, but $0 \%$ in staff. ${ }^{20}$ The municipal system reportedly did collect samples for Legionella culture analysis, which were all reported as negative shortly after the outbreak, but the location, sample collection method, and number of samples were not reported (SI-Section 4).

Other Possible Impacts Arising from a Lack of Corrosion Control. We have confirmed with the EPA that there were no legal requirements for this medium-sized municipal water system to collect data during the period when corrosion control was interrupted, and there were no water lead testing data collected during this time. Since implementing the LCR in the 1990s, Quincy has reported very low WLLs (90th percentile from 0 to $1.8 \mu \mathrm{g} / \mathrm{L}$ ), which qualified them for reduced monitoring requirements (i.e., collecting 30 samples every three years) as long as they do not violate the LCR action limit (90th percentile of $>15 \mathrm{ppb}$ ). Thus, they were not required to report the short-term changes in the treatment process to their primacy agency or to conduct additional monitoring during the lapse in phosphate dosing. During the 2015-2017 reporting period, the 90th percentile WLL increased to $9.2 \mu \mathrm{g} / \mathrm{L}$ (Figure 4A). Analysis of all paired data from homes sampled during each event that included at least one WLL above the quantification limit demonstrated WLLs during the 2015-2017 monitoring period were statistically higher when compared to that of either the 2012-2014 or 2018-2020 reporting periods (Figure 4A).

All of the samples for the 2015-2017 reporting period were collected in June or July 2017, which was 17 months after phosphate corrosion control was reinstated, suggesting there was potentially a long-term recovery period after phosphate was reintroduced. This long-term recovery period is consistent with the FWC, wherein elevated WLLs $(13.6 \mu \mathrm{g} / \mathrm{L})$ were still present 9 months after phosphate dosing was resumed during the FWC. ${ }^{18}$ However, a very large passivation dose of 
phosphate $(>3 \mathrm{mg} / \mathrm{L})$ to re-establish the effectiveness of resumed phosphate corrosion control was used during the FWC. ${ }^{28}$ In Quincy, normal phosphate levels were used until 1 month after the higher LCR monitoring data were reported in 2017; then the water treatment plant phosphate dose was increased from an average of $1.01 \mathrm{mg} / \mathrm{L}$ to a value of $2.37 \mathrm{mg} /$ L (Figure 2, gold dashed line, and SI-Section 5). The 20182020 LCR reporting period 90th percentile then decreased again to $<1 \mu \mathrm{g} / \mathrm{L}$. This decrease was significantly lower than that of the 2012-2014 reporting period (Figure 4A), consistent with the increased phosphate dose implemented after the increased WLLs were discovered during the 20152017 monitoring period.

Given that no lead-in-water samples were collected by the city during the period that phosphate corrosion control was interrupted or 17 months thereafter, we examined routine BLL monitoring data for children during this time period. The month immediately after phosphate corrosion control was discontinued in 2015, $10.7 \%$ of children under 6 years of age tested had BLLs of $\geq 10 \mu \mathrm{g} / \mathrm{dL}(n=65)$ relative to an average of $2.2 \%$ over the previous 10 years (Figure $4 \mathrm{~B}$ ). We note that this routine BLL monitoring data targets children most at risk of lead paint exposure, and not pregnant women or infants using formula who are at greatest risk of lead in water exposure. $^{29-31}$ We also note that this spike occurred in summer months, when BLLs are known to increase in some communities and Quincy's BLL monitoring data have had a similar sporadic increase (Figure 4B). However, a short duration spike in BLLs immediately after corrosion control was interrupted is consistent with trends during the FWC, where the BLLs spiked in the first few months of the crisis even though the level of lead in water remained higher for much longer. The BLL spike in Flint co-occurred with a spike in lead in wastewater biosolids, corresponding to rapid leaded scale destabilization. ${ }^{17,32}$ We attempted a biosolid analysis in Quincy, but unfortunately, biosolid data for the relevant time periods were not collected or able to be located by staff (SISection 6).

\section{IMPLICATIONS}

Here we hypothesized that the decrease in disinfectant residual in the municipal distribution system was a key event that precipitated a community-wide LD outbreak in Quincy, IL. The shifts in water quality detailed herein are consistent with increased Legionella growth potential and an LD outbreak, particularly at IVHQ where numerous other deficiencies were present and the population was susceptible (SI-Section 7). This "camel's back" hypothesis, i.e., from the idiom "the straw that broke the camel's back", wherein a seemingly small change finally precipitates a large reaction due to a number of preexisting issues, is supported by seven lines of publicly available data presented herein (i.e., using chloramine instead of free chlorine as a primary disinfectant, phosphate corrosion control lapse, low distribution system disinfectant residuals, elevated WLLs, elevated BLLs, elevated turbidity reflecting difficult treatability, and elevated community-acquired pneumonia or LD).

This study highlights the importance of holistic LD outbreak investigations and serious limitations in the LCR. Despite the municipal water treatment plant response of increasing disinfectant residuals throughout the distribution system and testing for Legionella, no problems with the Quincy distribution system water quality have been acknowledged. The outbreak investigation and subsequent lawsuits focused solely on deficiencies at the IVHQ. Interestingly, even though the municipal water supply was never recognized as a potential contributing factor to the 2015 LD outbreak in Quincy, IDPH and Illinois EPA nonetheless cited the event as a motivating factor for increasing the minimum disinfectant residual concentration requirements throughout the state (Section SI7). ${ }^{33}$ A definitive shared responsibility model, across all stakeholders, is urgently needed to better prevent LD in the future. ${ }^{34}$ There is increasing recognition of potential water utility responsibility in the management of Legionella risk in municipal water systems, ${ }^{35}$ but there are still significant uncertainties in how they should respond and communicate to the public about Legionella risks. ${ }^{35,36}$

A temporary lapse in corrosion control during water treatment plant upgrades is lawful for small systems under the current LCR, and increased WLL monitoring or public notification is not required. Due to the 3-year LCR reporting period in Quincy, no WLL data were collected during the 6month lapse in phosphate or for 17 months thereafter. Evidence from Flint and Washington, DC, suggests that lead scales can be destabilized almost immediately after interruption of corrosion control and may cause a spike in elevated BLLs. $^{30,32}$ Future revisions in the LCR should consider increased requirements for monitoring and public notification during interrupted corrosion control for small water systems.

Despite the international attention that the FWC attracted, little has changed in terms of policy and practice to protect public health from Legionella associated with municipal water system deficiencies. Flint is frequently viewed as an "extreme case" or an "anomaly" due to the severe water discoloration and illegal actions of regulators. Herein, we reveal a strikingly similar situation of interrupted corrosion control linked to LD cases and other water quality problems in Quincy, which occurred without any violation of the law or public acknowledgment of municipal water system problems. Distribution system monitoring regulations should be updated such that when major changes in water treatment or distribution system operation occur, increased monitoring of water quality, clinical surveillance for $\mathrm{LD}$, enhanced water management plan actions (e.g., flushing), and communication between utilities and their customers are triggered. Such changes may have saved lives if they had been implemented in either Flint or Quincy.

\section{ASSOCIATED CONTENT}

\section{S1 Supporting Information}

The Supporting Information is available free of charge at https://pubs.acs.org/doi/10.1021/acs.estlett.0c00637.

2015 community-acquired LD case investigation reports, record storm and hydraulic disturbances, underreporting of community-acquired legionellosis, Legionella sampling in municipal water, other concerns related to a lack of corrosion control, biosolid lead levels, and Quincy event timeline and similarities between Flint and Quincy LD outbreaks (PDF)

Freedom of Information Act request results (PDF)

Freedom of Information Act request results (PDF) 


\section{AUTHOR INFORMATION}

\section{Corresponding Author}

William J. Rhoads - Department of Civil and Environmental Engineering, Virginia Tech, Blacksburg, Virginia 24060, United States; 10 orcid.org/0000-0001-9325-4680; Phone: 417-4372550; Email: wrhoads@vt.edu

\section{Authors}

Tim Keane - Legionella Risk Management, LLC, Chalfont, Pennsylvania 18914, United States

M. Storme Spencer - Department of Civil and Environmental Engineering, Virginia Tech, Blacksburg, Virginia 24060, United States; 10 orcid.org/0000-0001-9255-3099

Amy Pruden - Department of Civil and Environmental Engineering, Virginia Tech, Blacksburg, Virginia 24060, United States; (1) orcid.org/0000-0002-3191-6244

Marc A. Edwards - Department of Civil and Environmental Engineering, Virginia Tech, Blacksburg, Virginia 24060, United States

Complete contact information is available at: https://pubs.acs.org/10.1021/acs.estlett.0c00637

\section{Notes}

The authors declare no competing financial interest.

\section{ACKNOWLEDGMENTS}

Funding for this work was provided by the State of Illinois. The State of Illinois did not contribute to the study design, analysis, or writeup. The authors acknowledge Dr. Sid Roy for his assistance in obtaining and analyzing the biosolid data from the Quincy municipal wastewater treatment plant and Maylin Waddel-Horren for her assistance in tabulating FOIA data.

\section{REFERENCES}

(1) Centers for Disease Control and Prevention. Legionella (Legionnaires' Disease and Pontiac Fever): Disease Specifics. https://www.cdc.gov/legionella/clinicians/disease-specifics.html (2020-09-16).

(2) Darelid, J.; Löfgren, S.; Malmvall, B. E. Control of nosocomial Legionnaires' disease by keeping the circulating hot water temperature above $55 \mathrm{C}$ : experience from a 10 -year surveillance programme in a district general hospital. J. Journal of Hospital Infection 2002, 50 (3), 213-219.

(3) Ciesielski, C.; Blaser, M.; Wang, W. Role of stagnation and obstruction of water flow in isolation of Legionella pneumophila from hospital plumbing. Appl. Environ. Microbiol. 1984, 48 (5), 984-987.

(4) Bédard, E.; Fey, S.; Charron, D.; Lalancette, C.; Cantin, P.; Dolcé, P.; Laferrière, C.; Déziel, E.; Prévost, M. Temperature diagnostic to identify high risk areas and optimize Legionella pneumophila surveillance in hot water distribution systems. Water Res. 2015, 71, 244-256.

(5) Garcia-Vidal, C.; Labori, M.; Viasus, D.; Simonetti, A.; GarciaSomoza, D.; Dorca, J.; Gudiol, F.; Carratalà, J. Rainfall is a risk factor for sporadic cases of Legionella pneumophila pneumonia. PLoS One 2013, 8 (4), e61036.

(6) Hicks, L. A.; Rose, C.; Fields, B.; Drees, M.; Engel, J.; Jenkins, P.; Rouse, B.; Blythe, D.; Khalifah, A.; Feikin, D.; Whitney, C. G. Increased rainfall is associated with increased risk for legionellosis. Epidemiol. Infect. 2007, 135 (5), 811-817.

(7) Mermel, L. A.; Josephson, S. L.; Giorgio, C. H.; Dempsey, J.; Parenteau, S. Association of Legionnaires Disease with Construction: Contamination of Potable Water? Infect. Control Hosp. Epidemiol. 1995, 16 (2), 76-81.

(8) Garrison, L. E.; Kunz, J. M.; Cooley, L. A.; Moore, M. R.; Lucas, C.; Schrag, S.; Sarisky, J.; Whitney, C. G. Vital signs: deficiencies in environmental control identified in outbreaks of Legionnaires' disease-North America, 2000-2014. MMWR 2016, 65 (22), $576-585$.

(9) Mautino, F. Performance Audit of Legionnaires' diesase as the Quincy Veteran' Home. State of Illinois. Office of the Auditor General, 2019. https://www.ilga.gov/reports/ReportsSubmitted/ 367RSGAEmail813RSGAAttach19-Quincy-Legionnaires-DiseasePerf-Full.pdf (accessed 2020-09-21).

(10) Cohn, P.; Gleason, J.; Rudowski, E.; Tsai, S.; Genese, C.; Fagliano, J. Community outbreak of legionellosis and an environmental investigation into a community water system. Epidemiol. Infect. 2015, 143 (6), 1322-1331.

(11) National Academies of Sciences, Engineering, and Medicine. Management of Legionella in Water Systems; The National Academies Press: Washington, DC, 2020..

(12) Cassell, K.; Gacek, P.; Rabatsky-Ehr, T.; Petit, S.; Cartter, M.; Weinberger, D. M. Estimating the True Burden of Legionnaires' Disease. Am. J. Epidemiol. 2019, 188 (9), 1686-1694.

(13) Binney, Z. O.; Nelson, K. N.; Chamberlain, A. Excess Pneumonia Mortality During a Legionnaires' Disease Outbreak in Flint, Michigan. medRxiv 2019, 19005942.

(14) Rhoads, W. J.; Garner, E.; Ji, P.; Zhu, N.; Parks, J.; Schwake, D. O.; Pruden, A.; Edwards, M. A. Distribution system operational deficiencies coincide with reported Legionnaires' disease clusters in Flint, Michigan. Environ. Sci. Technol. 2017, 51 (20), 11986-11995.

(15) Schwake, D. O.; Garner, E.; Strom, O. R.; Pruden, A.; Edwards, M. A. Legionella DNA markers in tap water coincident with a spike in Legionnaires' disease in Flint, MI. Environ. Sci. Technol. Lett. 2016, 3 (9), 311-315.

(16) Zahran, S.; McElmurry, S. P.; Kilgore, P. E.; Mushinski, D.; Press, J.; Love, N. G.; Sadler, R. C.; Swanson, M. S. Assessment of the Legionnaires' disease outbreak in Flint, Michigan. Proc. Natl. Acad. Sci. U. S. A. 2018, 115 (8), E1730-E1739.

(17) Hanna-Attisha, M.; LaChance, J.; Sadler, R. C.; Champney Schnepp, A. Elevated blood lead levels in children associated with the Flint drinking water crisis: a spatial analysis of risk and public health response. Am. J. Public Health 2016, 106 (2), 283-290.

(18) Pieper, K. J.; Martin, R.; Tang, M.; Walters, L.; Parks, J.; Roy, S.; Devine, C.; Edwards, M. A. Evaluating water lead levels during the Flint water crisis. Environ. Sci. Technol. 2018, 52 (15), 8124-8132.

(19) Wang, H.; Masters, S.; Hong, Y.; Stallings, J.; Falkinham, J. O. III; Edwards, M. A.; Pruden, A. Effect of disinfectant, water age, and pipe material on occurrence and persistence of Legionella, mycobacteria, Pseudomonas aeruginosa, and two amoebas. Environ. Sci. Technol. 2012, 46 (21), 11566-11574.

(20) Centers for Disease Control and Prevention. Epi-Aid 2015-037 Trip Report: "Undetermined source of an healthcare-associated outbreak of Legionnaire's disease-Illinois, 2015". http://www.dph. illinois.gov/sites/default/files/publications/cdc-trip-reportquincyil12. 31.15.pdf (2020-09-21).

(21) Eighinger, S. One year later, storm is still fresh in many minds. https://www.whig.com/article/20160710/ARTICLE/160709987 (2020-09-21)

(22) Bédard, E.; Trigui, H.; Liang, J.; Doberva, M.; Paranjape, K.; Lalancette, C.; Faucher, S. P.; Prévost, M. Local adaptation of Legionella pneumophila within a hospital hot water system increases tolerance to copper. bioRxiv 2020, DOI: 10.1101/2020.04.22.054569.

(23) Garner, E.; Brown, C. L.; Schwake, D. O.; Rhoads, W. J.; Arango-Argoty, G.; Zhang, L.; Jospin, G.; Coil, D. A.; Eisen, J. A.; Edwards, M. A.; Pruden, A. Comparison of Whole-Genome Sequences of Legionella pneumophila in Tap Water and in Clinical Strains, Flint, Michigan, USA, 2016. Emerging Infect. Dis. 2019, 25 (11), 2013.

(24) Borchardt, J.; Helbig, J.; Lück, P. Occurrence and distribution of sequence types among Legionella pneumophila strains isolated from patients in Germany: common features and differences to other regions of the world. Eur. J. Clin. Microbiol. Infect. Dis. 2007, 27 (1), 29-36. 
(25) Reimer, A.; Au, S.; Schindle, S.; Bernard, K. J. Legionella pneumophila monoclonal antibody subgroups and DNA sequence types isolated in Canada between 1981 and 2009. Laboratory Component of National Surveillance. Eur. J. Clin. Microbiol. Infect. Dis. 2010, 29 (2), 191-205.

(26) Illinois Department of Public Health. Legionnaires' Disease Response And Remediation At The Illinois Veterans' Home At Quincy, 2018. https://www.dph.illinois.gov/sites/default/files/ publications/legionella-report-ga-4-6-18-041718.pdf (2020-09-21).

(27) Joint Committee on Administrative Rules. Administrative Code. Title 35: Enviornmental Protection, Section 653.604 Distribution System Residuals. https://casetext.com/regulation/ illinois-administrative-code/title-35-environmental-protection/part653-design-operation-and-maintenance-criteria/subpart-fchlorination/section-653604-distribution-system-residuals (2020-0921).

(28) Roy, S. E.; Edwards, M. A. Efficacy of Corrosion Control and Pipe Replacement in Reducing Citywide Lead Exposure during the Flint, Michigan Water System Recovery. Environ. Sci.: Water Res. Technol. 2020, DOI: 10.1039/D0EW00583E.

(29) Edwards, M. A.; Triantafyllidou, S.; Best, D. Elevated blood lead in young children due to lead-contaminated drinking water: Washington, DC, 2001- 2004. Environ. Sci. Technol. 2009, 43 (5), $1618-1623$.

(30) Edwards, M. A. Fetal death and reduced birth rates associated with exposure to lead-contaminated drinking water. Environ. Sci. Technol. 2014, 48 (1), 739-746.

(31) Triantafyllidou, S.; Edwards, M. A. Lead ( $\mathrm{Pb})$ in tap water and in blood: implications for lead exposure in the United States. Crit. Rev. Environ. Sci. Technol. 2012, 42 (13), 1297-1352.

(32) Roy, S.; Tang, M.; Edwards, M. A. Lead release to potable water during the Flint, Michigan water crisis as revealed by routine biosolids monitoring data. Water Res. 2019, 160, 475-483.

(33) Tom Cullerton applauds move to prevent Legionella outbreaks. http://www.illinoissenatedemocrats.com/sen-tcullerton-home/7642tom-cullerton-applauds-move-to-prevent-legionella-outbreaks (202009-21).

(34) Pruden, A.; Falkinham, J. O., III; Edwards, M. A. State of Science and Reserach Needs for Opporunistic Pathogens in Premise Plumbing; Water Research Foundation: Denver, 2013.

(35) LeChevallier, M. W. Managing Legionella pneumophila in Water Systems. J. - Am. Water Works Assoc. 2020, 112 (2), 10-23.

(36) LeChevallier, M. W. Occurrence of culturable Legionella pneumophila in drinking water distribution systems. Water Science 2019, 1 (3), No. e1139.

\section{NOTE ADDED AFTER ASAP PUBLICATION}

The Freedom of Information Act Supporting Information file was revised and reposted September 24, 2020. 